\title{
RE-ENVISIONING INFRASTRUCTURES, RE-ARMING SUSTAINABLE (UNCONVENTIONAL) PUBLIC SPACES: FREE DESIGN EXERCISES FOR FURTHER IMPROVEMENT OF THE URBAN REGENERATION PROJECT FOR THE FERROCARRIL DE CUERNAVACA DISTRICT OF MEXICO CITY, MEXICO
}

\author{
GIUSEPPE CALDAROLA \\ Department of Architecture and Arts, IUAV University of Venice, Italy
}

\begin{abstract}
This study focuses on those new (unconventional) public spaces generated through the existing urban infrastructures transforming interventions. The case study is the regeneration of the urban district of Mexico City crossed by a local railway line, the Ferrocarril de Cuernavaca, still partially in use. After an international competition, the entire area has been recently transformed, basing on the urban regeneration "Bosque Urban Ferrocarril del Cuernavaca" project made up by the Gaeta Springall Arquitectos Office. This project can be shown as a "model", as a good design practice to develop new "third places of density", capable of managing the existing urban conditions complexity and generating new urban qualities, new liveable spaces: innovative public spaces are generated along a linear park of $4.5 \mathrm{~km}$ which crosses 22 different neighbourhoods with different social, economic and spatial conditions; new urban functions, formal/informal hybrid forms of living/using the city (or its parts) are settled or simply suggested. It follows "common" design topics of various interventions able to increase social, economic and spatial values and to completely change the existing urban condition by adding space, in-filling life. Following a case study approach, this study reports the results of a joint workshop, conducted by the "Laboratori Metropolitani" research group of the IUAV University of Venice and by professors and students of the Ibero-Americana University. Three projects, set up during the workshop and completed in three Master's degree theses in architecture, will be shown and described; necessary multidisciplinary approaches, core issues and design topics will be highlighted to characterize and to increase dialogues between academia and professional practice; to show different possible ways to use free design exercises (especially those developed through workshops and seminars) as useful tools to address shared reflections for further urban projects developments and to imagine other possible interventions to improve urban quality life.
\end{abstract}

Keywords: infrastructure, public space, collective realm, regeneration projects, liveable places.

\section{INTRODUCTION}

This study focuses on those public spaces, often unconventional, which are generated as a result of the transformation of existing urban infrastructures.

Their transformation results from simply necessary technical and technological adaptations or more comprehensive changes in their spatial settings or characteristics. It becomes more often an opportunity to trigger regeneration actions of whole (more or less extended) urban districts. The results, in terms of quality liveable spaces, are completely comparable in several cases, attested in different urban contexts and in equally different parts of the world. Regenerating urban infrastructures becomes an opportunity to widen the provision of public spaces and to make neglected or dismissed or traffic dominated areas more accessible. 
Several architectural and urban design projects, descending from common general principles and recurring guidelines, can be considered as "models": they report different ways for managing the existing urban condition due to generate new urban qualities. Generating innovative (more often unconventional) public spaces, in-filling new urban functions and mixed uses, overpassing zoning, introducing or simply suggesting formal/informal hybrid forms of living/using the city (or its parts), transforming the existing urban infrastructures by reacquiring them to the public realm can be indicated as "common" design topics. Resetting urban fabrics, redesigning places, recharging their characters and values can be considered as starting points, shared tools of different regeneration projects, with strong strategical values and figurative features: a "Common ground", by which, several contemporary metropolises are undertaking innovative policies and design features to rethink their existing conditions. In several cases - even if with situational differences - re-envisioning urban infrastructures and, contemporarily, generating or rearming the system of public spaces become opportunities, primary occasions to improve liveability.

Cities are expanding their dimensions or, at the same time and more frequently, are transforming entire internal parts (e.g. Jacobs [1]). High-impact interventions are rethinking and redesigning the built city "per parts", placing themselves in between the existing urban fabric: new policies and new design processes are being developed, activated and implemented to transform places, change their characters, increase their values; highly relevant projects are directly linked to the system of public spaces and to the transformation of urban infrastructures; equally directly, the projects themselves are aimed at establishing significantly different conditions of integration between their specific domains (both infrastructural and public spaces).

In particular conditions of urban complexity - as can easily be imagined in the largest contemporary metropolises - several plans and programs are under activation. From these, equally various interventions are descending with recurring characteristics and common topics. Common design topics can be identified under the public spaces systems formations, renovations and developments issues; contemporarily, recurring design topics can be found under the infrastructural formations and transformations. In the same urban contexts, interventions on public spaces are concentrated and, in successfully cases, the same interventions are able to trigger positive dynamics of transformation affecting larger portions (compared to the real perimeters of the project areas) of the urban fabric.

Managing the system of existing public spaces and increasing themselves, with their different levels of variations and integrations with the rest of the built city, seem to be a common denominator and, likewise, the main vehicle for transforming and implementing urban qualities, living qualities. Similar conditions can be found in a series of interventions, more directly related to the urban infrastructures, aimed at minimizing their impacts and their roles as barriers, interruptions, etc. It seems, in other terms, that successfully interventions directly descend from more balanced and integrated approaches which simultaneously address characteristics, needs and claims of both public spaces and infrastructural systems (e.g. Aymonino et al. [2], Gehl [3], [4]).

\section{COMMON DESIGN TOPICS, GESTURES AND OBJECTIVES IN TRANSFORMING CITIES, MANAGING COMPLEXITY}

In several metropolitan cases, recurring interventions emerge, mostly supported by public initiatives. They mainly concern old and new expansion areas, the construction of new urban infrastructures and the regeneration of existing ones, and the provision of services. These interventions allow metropolitan areas, already overcrowded with population, to achieve new 
modulated densities and to establish new metrics for fluxes of people and goods (e.g. Berghauser Pont and Haupt [5]).

Urban regeneration policies become more complex: several programmes and projects derive from public policies following top-down approaches; various projects derive from more or less spontaneous place-use practices based on bottom-up approaches to urban regeneration issues. Following general principles and shared outputs, several projects are orienteered to qualify the public realm in its various forms. Liveable places are generated, lasting conditions of urban sustainability and inclusiveness are achieved through integrated interventions that restore balanced (and more or less direct or mediated) relationship between urban infrastructures and public space systems. In successfully cases, the identity matrices of places are restored, consolidated and valorised; positive spill-over effects are achieved on the same placed or on the surroundings areas.

Although the geographical contexts are different and the numerical and dimensional data of each metropolitan context are equally different, a sort of "common ground" can also be traced by observation recent regeneration processes. These are aimed at the transformation of the inner areas. The calibres of the interventions are comparable in terms of scalar dimensions, types of generated spaces and functions that can be settled. These are triggered and supported by the growth in the numbers of inhabitants, by changes in their composition, by the needs to improve the spatial qualities and to increase the provision of services and infrastructures (e.g. Sim [6]).

Possible alternative ways to promote, manage and control urban transformations are being defined; places of concentration of regeneration projects, types of projects to be developed, actions to be undertaken, scenarios of new urbanity to be pursued are already emerging. These new trends are the results of a sort of surrender and new life cycle of public actions in controlling urban transformations. In other words, public policies are coming to be more precise through the promotion of innovative urban design and planning projects, often modifying the contents and previsions of the more general instruments of control and management of urban transformations. (e.g. Caldarola [7]).

In the last decade, the "Laboratori Metropolitani" programme of the Iuav University of Venice has investigated several contemporary metropolises; various case studies have been defined; recurring topics have been recognised and evaluated through actions of research by design. Different cities - as i.e., Sao Paulo, Dar es Salaam, Seoul, New York, Santiago de Chile, Hong Kong, Mexico City, Moscow, Nanjing - have undertaken recent urban regeneration actions, directly related to the two main topics of re-envisioning urban infrastructure and rearming the existing public space systems. In all these metropolitan cases, possible new urban condition scenarios and new life cycles assessments are tested: cities become an experimental laboratory of primary importance (e.g. Caldarola [8]).

The comparison of the results of the analyses carried out on the case studies has made it possible to understand that the future urban structures must derive from the construction of new visions for their internal parts; the construction of new urbanity scenarios must start from those "central" peripheries that represent the most problematic (and, for this condition, most lively) parts of the urban fabric. Intervening on new possible balances of existing urban densities is not only related to numerical evaluations: their data (in terms of volumes, proportional ratios between built and unbuilt areas, presence of open spaces and endowment of services compared to the number of inhabitants, etc.) can become triggers to explicate unexpressed quantitative and qualitative potentials: this, if used as opportunities to reverse trends of misuse, lack of uses and users (e.g. Uytenhaak [9]). Unresolved or malfunctioning inner urban areas - due to their positional characteristics, their visibility and visitability, the amounts of transits and connective potentials - have the capacity to trigger virtuous 
processes, to generate models, to extend the perimeters beyond the real size of the project areas, to produce conditions that can be exported and applied to larger parts of the metropolitan areas.

Urban regeneration actions in some of the major contemporary metropolises are supported or triggered by innovative public policies and/or more spontaneous practices. Several projects are activated dealing with spaces of different nature, conditions and configurations. Urban regeneration projects that follow the more general principle/objective of qualificationimplementation of public space go through gradual processes of densification and requalification of more or less central areas, characterised by conditions of abandonment or degradation and affected by phenomena of physical and social marginality (e.g. Koolhaas [10]).

Some of the world's metropolises show conditions that are not (at least not directly) comparable with the largest part of the European cities. Their size, the variety of transformations, the high-levels of physical-spatial and social inequalities, and the conditions of internal complexity make it almost impossible to imagine the formation of general plans or instruments for controlling and managing transformations. Forming complex urban design projects is more often preferred to the general plans assessment. Cities are more often transformed "per parts" (e.g. Caldarola [8]). Through urban projects, new life cycles are imagined for larger or smaller parts of cities. With this new central dimension, the urban project becomes an opportunity to define new cycles of public actions and allows cities to become a laboratory where "unconventional" interferences between different and evolving disciplinary areas can be addressed.

In the same contexts, urban projects are proposed following different plans and programmes, even conveying design competitions (as in the case study of Mexico City); the new urban projects concern spaces of different nature and configuration; although with different contextual variations, they descend from the more general principle/objective of qualification-implementation of public space; The new urban projects involve spaces of different kinds and configurations; although with different contextual variations, they derive from the more general principle/objective of qualification-implementation of public space. (e.g. Koolhaas [10]). Recurring topic of several projects is the implementation of urban public spaces. Addressing temporary or highly experimental and communicative interventions, possible solutions to local problems are explored. New public spaces are also generated with the direct involvement of citizens groups during the whole design process. Small-scale interventions are preferred as they allow to trigger virtuous regeneration dynamics on areas larger than those directly under transformation and to sustain effective long-term results (e.g. Lyndon and Garcia [11], Paans and Pasel [12]).

Through the actions of institutional research and of research by design promoted by the programme "Laboratori Metropolitani" of the IUAV University of Venice and conducted on case studies of contemporary metropolises, the aforementioned recurring dynamics have been verified and compared. Complex systems of mostly public and spontaneous actions with virtuous processes of urban regeneration have been inventoried and described. The research was also structured through educational programmes, in particular, through seminars and onsite workshops. These were activated to accompany the institutional actions with free design exercises that allowed to experiment integrated, multidisciplinary and multi-sectoral approaches and to generate multi-scalar scenarios. Recurring project topics concern the regeneration of abandoned or partially dismissed areas, characterised by low levels of use or spontaneous practices of inhabiting places, delimited by infrastructures that generate barriereffects or by incongruous elements if compared to the pre-existing urban fabric and road networks. The interventions mainly focus on those spaces commonly defined as "Neglected 
spaces", "Lost spaces", "24 hours spaces", "Invaded spaces", "Exclusionary spaces", "Consumption spaces", "Privatized spaces", "Specialized or Technical spaces" (e.g. Koolhass [10]). Projects for their recycling and reuse become opportunities to imagine new uses and chapters of life (e.g. Marini and Corbellini [13]).New public policies of urban regeneration are under activation with top-down approaches; new spontaneous practices of appropriation (or reappropriation) and reuse of different places are emerging by bottom-up approaches and initiatives. Various renovation areas have been already transformed or have been identified as "resources", "starting point" for more complex developments; this, especially for achieving the more general objective of making the cities in themselves more liveable and sustainable

Ways of living and using places are becoming central design themes as well as the direct involvement of citizens in the conception and design processes. Alternative urban scenarios are being produced to explore alternative possibilities and to establish different conditions (e.g. Schenk [14]). Specific policies and projects are under development to identify and avoid (or, at least, minimise) the impacts of all those elements that can act as barriers, limits, preclusions due to generate new urban conditions of continuity and connection in those places, currently characterised by discontinuity, physical and social marginality, misuse, etc (e.g. Berghauser Pont and Haupt [5]). New squares, boulevards and green areas are being generated to increase the number of places for staying and gathering (e.g. Gehl and Svarre [15]). These interventions change the character of those places which can only be considered as transitional ones. New revitalised networks of covered and open-air streets and passageways are being created to make those places more recognisable as suitable for outdoor living (e.g. Colville-Andersen [16], Sadik-Kahn and Solomonow [17]). Public transport is being managed and cycling and pedestrian accessibility is being improved. New integrated programmes of materials and street furniture are improving the recognisability of places. Urban spaces are becoming greener. Liveable places are being generated and their liveability in itself becomes more often the principal indicator of the quality of design (e.g. Stipa [18]).

\section{AN INTRODUCTORY LECTURE OF THE STUDY CASE OF THE FERROCARRIL DE CUERNAVACA DISTRICT REGENERATION PROJECT IN CDMX: FROM A RAILWAY LINE TO A LINEAR PARK}

Mexico City is remarkable as a highly relevant case study, compared to the other cities investigated by the "Laboratori Metropolitani" program.

The entire metropolitan area presents complex and alternative urban conditions, comparable to the other metropolitan cases in terms of quantities and qualities of the numbers of inhabitants, population, areas undergoing transformation, public policies and private initiatives with more or less significant effects on the urban fabrics. Because of these specific conditions, some of the transformations attested in Mexico City can be indicated not only as case studies. They can also be identified as good practices of design and implementation.

Particularly significant in the ongoing debate on the transformability of the city, on the urban regeneration issues, on new buildings and construction and on urban transformations is what is being built along the extension of the Ferrocarril de Cuernavaca.

The regeneration interventions of the urban district of Mexico City, crossed by a local railway line, are central in terms of location. They are highly significant for the positive impacts both in physical transformation of the involved urban spaces and in practices of use of the places: This is the urban district, composed of 22 different neighbourhoods, characterised by the presence of the Ferrocarril de Cuernavaca railway line. The reactivation and regeneration of residual urban spaces, including those corresponding to partially or totally dismissed railway tracks, is a widespread strategic effort. It is recurrent in various 
actions aimed at reopen to the public use dismissed parts of cities or those suffering from spatial and social marginalisation. The Ferrocarril de Cuernavaca area was transformed into a linear park on the basis of the transformation previsions of an international competition by invitation, open to groups of urban designers, architects and landscape architects. The overall objective of the competition was to transform the infrastructure site and its surroundings into a dynamic public space. The participants in the competition were asked to develop projects that would enhance the historical features of the site, meet the demand for green spaces, recreational and relational places, by identifying innovative proposals for the renovation of the railway infrastructure. A linear public space had to be the result, where the landscape intervention had to become an opportunity to improve the soil permeability and to provide the area with a technical infrastructure for a sustainable water management. In the competition announcement, the main targets were oriented towards the sustainability of the interventions, the adoption of multi-scalar design solutions, the introduction of mixed uses, the integration with urban stakeholders and social inclusiveness.

Based on the objectives of the international competition (2016), the entire area was transformed, following the urban regeneration project "Bosque urban Ferrocarril de Cuernavaca" which was established, under public promotion, by the Gaeta-Springall Arquitectos Office (Fig. 1). The project pursues approaches that can be adapted as "common" to various interventions, capable of increasing social, economic and spatial values and completely changing existing urban conditions by adding spaces, bringing life to places.

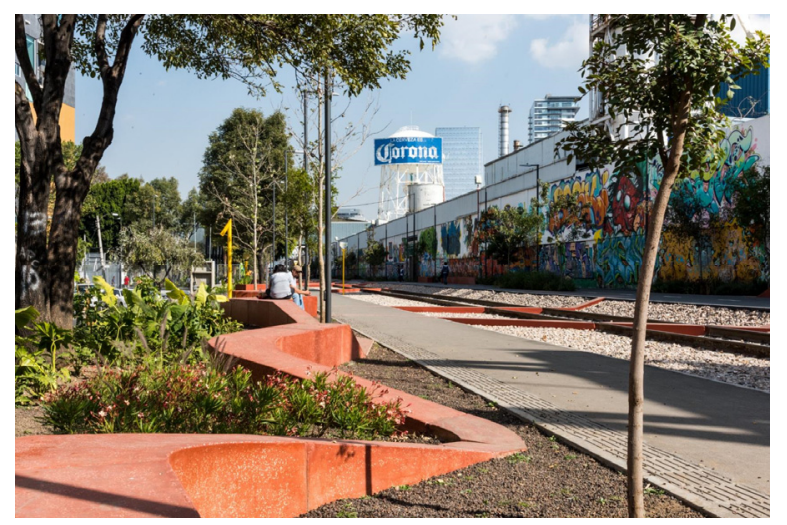

Figure 1: First section of the "Bosque Urban Ferrocarril de Cuernavaca" project.

The partially dismissed local railway track is the real marker of the whole district. It is a linear infrastructure, characterised by low levels of use, which crosses several neighbourhoods, significantly different in terms of social composition and urban conditions. Along the railroad, a linear park - the "Bosque Urbano Ferrocarril de Cuernavaca" project is progressively giving back to the city an infrastructural space that, until the beginning of the regeneration interventions, was privatised and affected by different, spontaneous and uncontrolled uses by the citizens. By mixing design processes with direct participative programs for the population, the formation of the linear public space Bosque Urbano FLCC, alongside the infrastructure, became the main opportunity to develop an urban quality project in Mexico city. The project proposal aimed to generate a linear park as a $4.5 \mathrm{~km}$ long urban forest; to cross over 22 different neighbourhoods (different in terms of social, economic and spatial conditions and values); to build a civic, democratic, active, programmatic, inclusive, 
sustainable, connecting space; to create a continuous space, easily readable and recognisable space, which is identity-based and capable of contributing to contribute to the community spirit; and to enhance the senses and practices of appropriation of public space by inhabitants and external users.

Starting from the closing of the competition (2016) and within the first year, the first $1.4 \mathrm{~km}$ section of the whole intervention extension $(4.5 \mathrm{~km})$ was completely realised and opened to the public. The executive project was developed interacting with different governmental stakeholders and by socialising and evaluating the overall strategy and specific design issues with the inhabitants and with the neighbourhood groups, each of whom operate in the same places and have a strong sense of ownership and belonging. In its totality and within the construction made by three different and subsequent phases, the project has generated a linear urban forest of $4.5 \mathrm{~km}$ in length. It has generated significantly different urban conditions; it has generated a new system of interconnected public spaces, each one directly located along the linear element of the railway line; it has added values to strengthen the sense of community, the sense of belonging. The project has more over contributed to the growth and transformation of the extended urban district; it has generated a new and necessarily balanced relationship between housing schemes and mixed uses; it has brought about new balances between developments and economic and social values, preserving those elements considered as belonging to the heritage and maintaining transformational conditions for their surroundings.

The project established not only a linear and continuous public space (with the same extension of the infrastructural line) with public facilities, but also a green area, achieving several social, economic and environmental benefits. The establishment of an urban forest addressed a unique and qualified condition with environmental and social benefits, from air quality issues, noise reduction to educational issues and community ownership and empowerment. The whole project consists of simple elements: a Red Line, which marks the entire linear development of the project area, avoiding walls and barriers, acting properly as an anti-wall and anti-boundary, as a programmatic gesture to suggest and indicate a system of permeable boundaries; Folies of water, to mark the presence of the water element, built along the entire extension of the linear park, and to mark and give importance and centrality to the self-sufficiency of the intervention and of the maintenance cycles; a continuous playground area, in order to achieve the objective of generating a friendly public space, especially modelled on the necessities of younger users, which can be deduced through labs and activities carried out with the direct participations of the inhabitants. All constituent elements were derived from direct involvement of the inhabitants in the decision-making processes.

All the actions of the project have been developed and framed within five clear objectives, such as: increasing social values, obtained by imagining a design process, in each phase of its development, directly established by and for the inhabitants and the neighbourhoods groups; maintaining identity and memory, through the generation of easily recognisable places, with a new general layout directly integrated with pre-existing elements; generating sustainable, liveable and quality places by addressing social, economic and spatial benefits; managing multi-scalarity, adding the possibility of further developments within the same areas of interventions or at its margins and boundaries or outside its perimeter; calming all costs of interventions, both on the initial implementation of the project and on maintenance cycles. 


\section{FREE DESIGN EXERCISES, ENVISIONING NEW URBANITIES CONDITIONS, ADDRESSING QUALITY LIFE}

The "Bosque Urban Ferrocarril de Cuernavaca" project can be indicated as a "model", as a good design practice. The entire area of the Ferrocarril de Cuernavaca can be considered as "third place of density". It was affected by spontaneous practices and uses that had already transformed the specialized space of the railway line in a transitional and relational space with high social values for the inhabitants of the different neighbourhoods. The project idea was able to manage the complexity of the existing urban conditions and to generate new urban qualities, new liveable spaces. Innovative (unconventional) public spaces have been generated from the interventions on the existing railway infrastructure. The railway line was kept in operation and integrated into the project: the choice to use the red line as a marker in plan, instead of placing walls and other barriers in elevation was guided by the technical and technological requirements of the infrastructure. The new linear park - extended for $4.5 \mathrm{~km}$ between different various neighbourhoods with equally diverse social, physical-spatial and economic conditions - in its linear development, intercepts the civic cultural district, formal and informal settlements mainly characterized by residential or commercial uses, green areas, market areas, some of the main roads corridors and other infrastructural lines.

Throughout this series of different conditions, the project has established, incorporated (or simply suggested) new urban functions, hybrid formal/informal forms of living/using the city (or parts of it).

As clearly appreciable from the description contained in the previous section, the "Bosque Urban Ferrocarril de Cuernavaca" project can certainly be indicated as a good practice of design, management of the ideational process and consensus formation by the resident population as well as their direct involvement in the whole process. It can certainly be indicated as a complete project in itself, and capable of generating significant economic, social and spatial benefits.

In the same way, it can be said - as in the declared intentions of the design team - that the project has a variable perimeter: by breaking its physical limits - those foreseen and established by specific requirements of the international competition - it opens up to subsequent developments, to further transformations that may be take place within the same area affected by the interventions, as well as, along their perimeter, admitting the possibility of supporting them with further urban regeneration projects.

Following a case study analysis approach, this study collects some of the most significant results of a joint workshop, conducted by the research group "Laboratori Metropolitani" of the IUAV University of Venice and by professors and students of the Ibero-Americana University in 2018. Three projects, set up during the workshop and completed through three master's degree theses in architecture, are shown and described; the necessary multidisciplinary approaches, central themes and design actions to characterize and to implement the dialogue between the academic and professional practices fields are highlighted. Possible alternative ways of using free design exercises (especially those developed in on-site workshops and seminars) are suggested as useful tools to initiate, introduce and complete shared reflections. Through actions of research by design, possible extensions of the project areas are identified, further themes are developed, adding other design topics and multi-disciplinary approaches, and to imagine others possible interventions aimed at improving the quality of life in cities.

The project (Fig. 2) "The Origins. A Golden Stream in CDMX" (Author: Francesca Pasquali; Supervision: Professor Aldo Aymonino; Co-supervision: Architect Giuseppe Caldarola) suggests the possibility of transforming the linear system, defined by the linear park project along the Ferrocarril route, into a circuit, into a continuous circular public 
pedestrian area. To achieve this result, the project starts by rediscovering the ancient traces that characterised that part of the city, those that existed before its urbanization and that have been covered or erased over the last centuries. It achieves this result by suggesting or indicating a series of interventions on the street sections to characterise the use of the streets not only as transitional spaces but, also and above all, as a relational space.

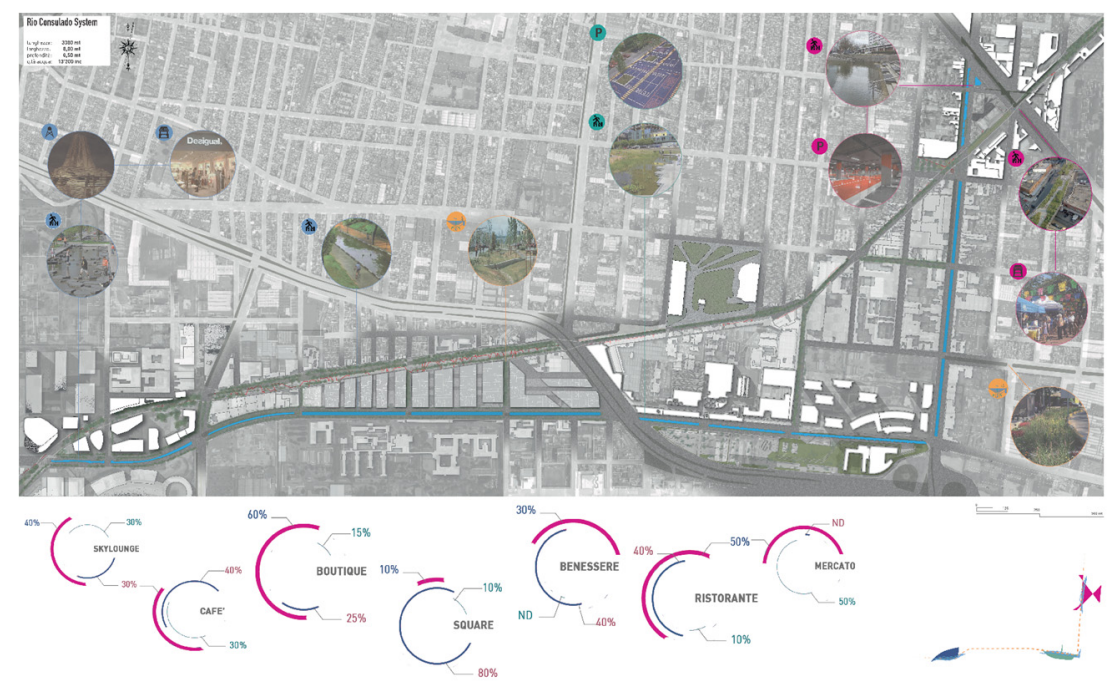

Figure 2: Masterplan of the "The Origins. A golden stream in CDMX" project.

The project suggests the possibility to further implement the network of cycle and pedestrian pathways, characterised by "slow" walkability and usability; to enlarge the network of public spaces, forming new ones; to add functions and different possibilities of use and fruition of the same spaces, improving their readability, recognisability and interconnections. These objectives are achieved by using the "water" element and its presence (currently denied or covered) within the city as an opportunity for urban regeneration, for increasing the quality of living and experiencing places, for forming new public spaces, socially addicted.

It is well known that the urban fabric of Mexico City (at least, its more central areas) insists on the sediment of an ancient lake and on a series of canals. Through the reading of historical maps and through mapping actions, the author of the project has been able to identify the presence of an ancient Rio - the so called, Rio Consulado - which was covered in past time. The ancient Rio (still covered) intercepts the Ferrocarril route in two points, closely positioned to the initial and final sections of the area affected by the transformation of the railway infrastructure into a linear park. Through the actions of de-layering and relayering, the author has been able to identify pre-existing functions, to highlight functional deficiencies, to identify critical issues, to evaluate and assess which areas could be integrated into the project to act as resources, to weigh alternatives, to suggest opportunities, to refine the project strategy and give it a specific character that would increase the overall imaginative values of the places. Starting from the road intersections near the entrance points of the Linear Park and following the path of the covered canal, the project proposes its partial reopening; it forms a further linear system, composed as an annular sequence of relational public spaces. 
Along the rediscovered route, these spaces are formed as places for staying, places for gathering, places for cultural events and markets. These new relational spaces are formed and connected by a continuous pedestrian pathway, located at a lower level than the road one but directly accessible from it at several points, suitable for improving connections with the neighbouring urban fabric.

The project focuses on three key points; it assigns a general image and deeply characterises the places; it assigns them a specific architectural layout. The first focus is near the cultural district, just in front of the public area marked by the presence of several museums. Staircases and ramps mark the entrance to the new linear public space along the rediscovered canal; a small plaza introduces the sequence of small open-air pavilions, adaptable to different uses (spaces for temporary exhibitions, market places, etc...) and new pedestrian routes. The second focus is directly connected to the entrance of the Modelo brewery: here the project suggests to place a multi-level, mixed-uses building that can serve as a landmark, a new green area and sports facilities. The third focus area is directly close to the end of the second section of the Linear Park (actually, the project made by the GaetaSpringall Office is carried up to that section). Here the project suggests the construction of a small plaza, connected to the existing street level by staircases and ramps, with a multifunctional pavilion, covered by a high tech roof capable of regulating the alternation of lights and shadows and microclimatic conditions. The technical artefacts are arranged along the entire extension of the new linear public space along the stream.

The second project "Mexico 18. Mixing den-city" (Author: Alberto Bressan; Supervision: Professor Aldo Aymonino; Co-supervision: Architect Giuseppe Caldarola) insists on the second focus area of the previous project. It follows the prevised general layout for the area; it explores the possibilities of increasing the roles of the new green areas settled and the sports facilities located; it works deeper at the architectural scale to address a more complete reflection on the opportunity to increase densities (volumetric and functional ones). These objectives are achieved by designing a new high-density, mixed uses tower that overlaps a public podium directly accessible from an aerial pedestrian pathway: a sort of "pedestrian highway", with its sprawling tentacular unvolumetric structure, bypasses one of the most traffic dominated roads of Mexico City (the Avenida Cervantes); it establishes direct connections with the residential neighbourhoods that are located on the opposite side of the street; it marks the entrance point to the new public spaces, to the recreational spaces and to the sport facilities; it generates new direct connections with the Modelo Brewery, overpassing its fences and reaching the Ferrocarril Linear Park. This project suggests alternative possibilities to enhance the qualities and quantities of the existing public spaces and to set new multi-levels ones, following general recurring design principles derived from different experiences of formation/implementation of public spaces in high-density contexts.

The third project (Fig. 3) "The Big Bundle" (Authors: Davide Castegnaro, Luca Rizzo, Gianluca Trovò; Supervision: Professor Aldo Aymonino; Co-supervision: Architect Giuseppe Caldarola) is located in the ending point the third focus area of the first project. It is placed along one of Mexico City's main traffic corridor, where is located the north-eastern entrance point to the Linea Park. The entrance is marked with a multifunctional megastructure. The project suggests and explores the possibilities of adding architectural objects, of different scalar presences (if compared with the existing urban fabric all around), that can act as landmarks, as indicators that something new can happen in that point. The new megastructure, almost completely unvolumetric, consists of a continuous sequence of multilevel pedestrian pathways serving versatile spaces, suitable for installing different temporary functions. 


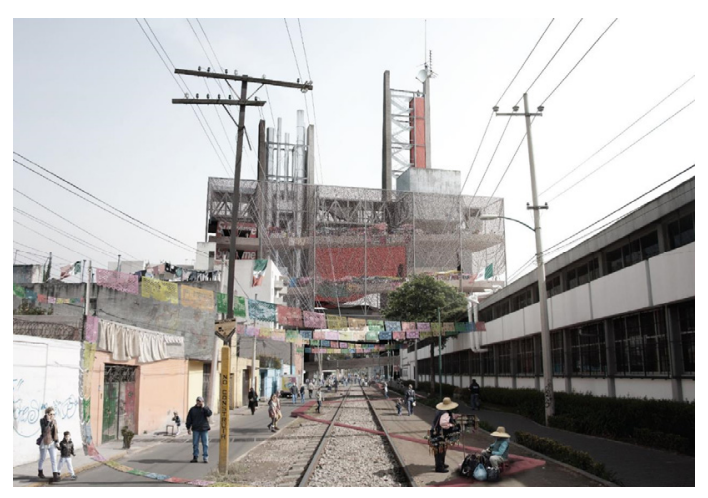

Figure 3: Render of "The Big Bundle" project.

Within the same unvolumetric building, the basement and the ground levels collect the connections with the underground station and the bus stops and with the system of neighbouring public spaces; the parking areas are disposed on one of the two underground levels. By applying traffic calming techniques, the existing roads network is transformed into a woonerf (fast vehicular traffic is moved to the first underground level). This type of intervention has a strong strategical value because it allow the possibility to reduce the actual role of the street that acts as a barrier disposed between two residential areas which aim to be more interconnected. At the ground level, a new roads system is generated in forms of traffic calmed, more pedestrian friendly, roads network directly connected to the upper multilevel public space. Among the suggested public functions is the possibility of using the megastructure as a kind of vertical market. The spaces for temporary markets allow in fact to maintain and amplify the existing ways of using and living the places: in the same site in fact, through the mapping actions, the design team has recorded the presence of a daily market that, when set up, completely changes the current way of using the street space. in fact, it is well known the role of market places in adding social and liveable values to the places).

The "free" character of these design exercises is simply appreciable as a possible way to equally "free" admittance, within the ongoing public debate on urban regeneration projects, of alternative visions and indications. These free design exercises, included in this study, are meant to be indicated as exempla of possible alternative strategies for further improvements of the ongoing urban regeneration processes. However with a certain level of approximation, they admit the possibilities of constructing visions, scenarios not directly set up to respond to the claims, rules and prescriptions required by the public commitment. They make it possible to widen the perimeters of the areas of intervention, to suggest alternative or complementary strategic directions with respect to the current transformations. They allow some professional practices to be reopened to different multidisciplinary suggestions and approaches and to indications coming from academic efforts and, vice versa, they allow academic approaches to be brought closer to professional practice.

\section{ACKNOWLEDGEMENTS}

This paper is based on the research results of the "Laboratori Metropolitani" program which is coordinated by the author join with the architect Roberta Bartolone. Laboratori Metropolitani is a 4-year research and teaching program opened to Italian universities students in architecture, established by the IUAV University of Venice jointly with several foreign universities. The program was activated with the aim of developing research on issues 
relating to the implementation of sustainable development models for selected contemporary metropolises cases, characterized by strong expansion and/or transformation dynamics. The scientific committee is composed by professors A. Aymonino, E. Fontanari, P. Bonvini, G. Mondaini, R. Simone and other professors of the foreign universities to whom special thanks by the author of this paper have to be addressed for their contribution of ideas. Editions/cities: São Paulo, Brazil, with the Universidade de São Paulo (USP) - Faculdade de Arquitetura e Urbanismo (2011); Dar es Salaam, Tanzania, with the Ardhi University of Dar es Salaam (2012); Seoul, Korea, with the SKKU University of Seoul (2013); New York with the Parsons New School of Design (2014); Santiago, Chile, with the Universidad Diego Portales (2015); Hong Kong with the Polytechnic University of Hong Kong (2016); Mexico City with the Ibero-American University (2017); Moscow with the Moscow Institute for Architecture (2018); Nanjing with the Southeast University of Nanjing (2019). The laboratory, with annual programming, is structured in a cycle of introductory lessons, a study trip with on-site surveys and 2-week workshops plus an 8-week intensive workshop in Venice during which the first analyses and design ideas, as emerged during the workshop abroad, are deepened, completed and reassessed in a final exhibition and in a seminar.

\section{REFERENCES}

[1] Jacobs, J., Vita e morte delle grandi città, Italian ed., Einaudi, 2009.

[2] Aymonino, A., Bartolone, R. \& Caldarola, G., Laboratori metropolitani Riciclare città. Esercizi di postproduzione, Quaderni della ricerca del Dipartimento di Culture del Progetto, Iuav, ed. S. Marini, Aracne ed., Rome, pp. 90-109, 2014.

[3] Gehl, J., Cities for People, Island Press, 2010.

[4] Gehl, J., Life Between Buildings: Using Public Space, VI ed., Island Press, 2011.

[5] Berghauser Pont, M.Y. \& Haupt, P.A., Spacemate: The Spatial Logic of Urban Density, Delft University Press Science: Delft, 2002.

[6] Sim, D., Soft City: Building Density for Everyday Life, Island Press, 2019.

[7] Caldarola, G., Metropoli come laboratorio: da piani, programmi e progetti a esperienze di didattica e ricerca. Proceedings of the XXI Annual SIU Conference, Confini, movimenti, luoghi. Politiche e progetti per città e territori in transizione, in Planum Journal of Urbanism, 2019.

[8] Caldarola, G., Metropoli come laboratorio: da piani, programmi e progetti costruiti a esperienze di ricerca e didattica. Proceedings of the XI INU Study day, Interruptions, Intersections, Sharing and Overlapping. New Perspectives for the Territory, ed. F.D. Moccia and M. Sepe, Urbanistica Informazioni, n. 278 special issue, INU edizioni, 2019.

[9] Uytenhaak, R., Cities Full of Space: Qualities of Density, 010 Publishers: Rotterdam, 2008.

[10] Koolhaas, R., Junkspace: Per un ripensamento radicale dello spazio urbano, Quodlibet, 2006.

[11] Lyndon, M. \& Garcia, A., Tactical Urbanism: Short-Term Action for Long-Term Change, 3rd ed., Island Press, 2015.

[12] Paans, O. \& Pasel, R., Situational Urbanism: Directing Postwar Urbanity. An Adaptive Methodology for Urban Transformation, Jovis ed., 2014.

[13] Marini, S. \& Corbellini, G., Recycled Theory: Dizionario Illustrato/Illustrated Dictionary, Quodlibet, 2016.

[14] Schenk, L., Designing Cities. Basics, Principles, Projects, Birkhauser ed., Basel, 2013.

[15] Gehl, J. \& Svarre, B., How to Study Public Life, Island Press, 2013. 
[16] Colville-Andersen, M., Copenhagenize: The Definitive Guide to Global Bicycle Urbanism, Island Press, 2018.

[17] Sadik-Khan, J. \& Solomonow, S., Streetfight: Handbook for Urban Revolution, Penguin Group, USA, 2017.

[18] Stipa, A., Il disegno urbano nasce dalla densità di funzioni, significati e potenzialità. Interview in Controspazio, 2, pp. 46-63, 1994. 